\title{
Evaluation of the quality of life of ovarian cancer patients in the context of selected quantitative variables such as body mass, number of miscarriages and time from diagnosis
}

EWA PERKOWSKA ${ }^{1, A-G}$, SŁAWOMIR TERLIKOWSKI ${ }^{2, A, ~ D-F}$, ROBERT TERLIKOWSKI ${ }^{3, A, ~ D-F}$, ORCID ID: 0000-0002-0815-216X

ALICJA MOCZYDŁOWSKA ${ }^{4, B, E}$, TERESA MARKOWSKA ${ }^{5, B, F}$, LUDMIŁA MARCINOWICZ ${ }^{1, E, F}$

${ }^{1}$ Department of Primary Health Care, Medical University Bialystok, Poland

${ }^{2}$ Department of Obstetrics, Gynaecology and Maternity Care, Medical University Bialystok, Poland

${ }^{3}$ Department of Rehabilitation, University Teaching Hospital Bialystok, Poland

${ }^{4}$ College of Agribusiness, Lomza, Poland

${ }^{5}$ Independent City Hospital PCK, Bialystok, Poland

A - Study Design, B - Data Collection, C - Statistical Analysis, D - Data Interpretation, E - Manuscript Preparation, F - Literature Search, G - Funds Collection

Summary Background. Epidemiological reports show a systematic growth of incidences of ovarian cancer. The treatment for this type of cancer is associated with substantial physical and psychological burden on the patients.

Objectives. The aim of the current study was to compare the quality of life of patients treated for ovarian cancer and to evaluate the impact of selected quantitative variables.

Material and methods. A questionnaire study was carried out among 101 patients of the Oncological Gynaecology Ward of Maria Sklodowska-Curie Oncology Centre in Białystok. The control group was 100 healthy women undergoing routine periodic health examinations. In order to evaluate the women's quality of life, we used the European Organisation for Research and Treatment of Cancer (EORTC) questionnaires: Quality of Life Questionnaire Core 30 QLQ-C30, module for ovarian cancer QLQ-OV28 and an original questionnaire concerning the respondents' sociodemographic data.

Results. The evaluation of the respondents' overall quality of life showed that the quality of life of women with ovarian cancer is much lower than that of healthy women. Only in the area of gastrointestinal complaints and cognitive functions were there no statistically significant differences, and the $p$-factor was as follows: cognitive functions -0.066 , constipation -0.212 , diarrhoea -0.287 . Regarding sociodemographic factors, it was shown that BMI of women ranged from 18.07 to 44.64 . The study showed that women with a higher body mass index had more intensive peripheral neuropathy symptoms and side effects from chemotherapy. The time from the diagnosis of the disease to the implementation of the treatment in most cases did not exceed 10 years. A longer time lapse from the diagnosis to the beginning of treatment was associated with more intensive side effects of chemotherapy.

Conclusions. The study showed that patients undergoing treatment for ovarian cancer had reduced quality of life in terms of both physical and mental state as compared to healthy women. Sociodemographic factors have an important effect on patients' quality of life. Key words: ovarian neoplasms, quality of life, depression.

Perkowska E, Terlikowski S, Terlikowski R, Moczydłowska A, Markowska T. Evaluation of the quality of life of ovarian cancer patients in the context of selected quantitative variables such as body mass, number of miscarriages and time from diagnosis. Fam Med Prim Care Rev 2019; 21(4): 355-359, doi: https://doi.org/10.5114/fmpcr.2019.90167.

\section{Background}

Ovarian cancer is one of the most common causes of death from cancers of the female reproductive organs. The number of incidents differs depending on the geographical region. The lowest rates are in Chile and Japan, and the highest in Western Europe and the USA [1]. In Poland, the incidence of ovarian cancer is $11.2 / 100,000$. More than 3,000 new incidents are reported annually, which means this cancer is the fourth most common cause of death after lung cancer, breast cancer and colon cancer [2]. Ovarian cancer is one of the few cancers of the female reproductive organs that occur in young women, even those under 25 years of age [3]. The frequency of occurrence escalates sharply at around 40 years of age and increases steadily up to the age of 80 [4].

A comparison of the benefits resulting from prolonging disease-free survival with the toxic effects of treatment affecting the quality of life (QoL) has become an important element in clinical trials among cancer patients [5]. Thanks to evaluating the quality of life of female oncological patients in the context of selected clinical, demographic and environmental factors, it is possible to apply a number of measures aimed at improving those patients' quality of life.

\section{Objectives}

The aim of the current study was to compare the quality of life of patients treated for ovarian cancer and to evaluate the impact of selected quantitative variables such as body mass, number of miscarriages and the time from diagnosis on quality of life.

\section{Material and methods}

\section{Setting and ethical consideration}

The recruitment of women for the study began in December 2013 and was completed in November 2014. Permission for the 
study was approved by the Bioethical Commission of the Medical University of Białystok (Resolution No. R-I-002/71/2015)

\section{Participants}

A questionnaire study was carried out in 2014 among 101 patients of the Oncological Gynaecology Ward of Maria Sklodowska-Curie Oncology Centre in Białystok. The condition for participation in the study was confirmed diagnosis of ovarian cancer and the written informed consent of the patient. The control group consisted of 100 women who had not been treated for ovarian cancer and were subject to routine periodic examinations in the gynaecological clinic.

\section{Statistical methods}

To evaluate the quality of life, we used the European Organisation for Research and Treatment of Cancer (EORTC) questionnaires: the core version QLQ-C30 (v 3.0) and EORTC QLQOV28 for ovarian cancer patients. The respondents also filled in a questionnaire concerning data such as: age, parity, the number of miscarriages, time from diagnosis and body mass. The values of each subscale of the QLQ-C30 questionnaire were calculated using the methodology described in the "EORTC QLQC30 Scoring Manual" [6]. To present the distribution of scale values in subgroups, we used the arithmetic mean and standard deviation, as well as the median and extreme values. Groups were compared using the Mann-Whitney or Kruskal-Wallis tests. When comparing the distribution of qualitative and order characteristics between the subgroups, we used Pearson's chi-square test for independence. The tests were supplemented with an analysis of standardised residuals to identify contingency table cells with a significant difference between the observed and expected numbers, contributing to a significant result in the chi-square test. Relations between the quantitative variables were evaluated using nonparametric Spearman's rank correlations. Statistical calculations were performed using IBM SPSS Statistics v. 20.0. Statistical hypotheses were verified at a significance level of 0.05 .

\section{Results}

\section{Participants}

The study was conducted among patients treated for ovarian cancer. The control group consisted of women who had not been treated for ovarian cancer and were included in routine periodic examinations in the gynaecological clinic.

\section{Characteristics of the group of patients with ova- rian cancer}

The mean age of the respondents was 55 years. Almost $60 \%$ of patients lived in a big city. More than $40 \%$ of respondents had higher education. Professionally active patients constituted a similar group of $40 \%$, and almost half of them were retired. The average BMI of respondents was 26 .

\section{Characteristics of the group of healthy women}

Similarly to the group of ill patients, almost $60 \%$ of the respondents lived in a big city. Professionally active people constituted $97 \% .77 \%$ of respondents had higher education. The average BMI of these women was 25 , and the average age was 40 years.

\section{Main results}

The evaluation of the respondents' overall quality of life, using the QLQ-C30 questionnaire, showed that the quality of life of women with ovarian cancer is much lower than that of healthy women. Table 1 presents the mean values of the studied variables, the median and standard deviations, as well as the results of the Mann-Whitney test. The higher the results, the better the quality of life. The findings show that the quality of life in the group of healthy women was better than in the group of women with ovarian cancer. Healthy women obtained better results than ill women in most analysed areas. The only areas with no significant differences were digestive system problems (constipation and diarrhoea) and cognitive function.

\begin{tabular}{|c|c|c|c|c|c|c|c|c|}
\hline Group & & $n$ & Mean & $\begin{array}{l}\text { Standard } \\
\text { deviation }\end{array}$ & Min & Median & Max & $p^{*}$ \\
\hline \multirow{2}{*}{$\begin{array}{l}\text { QLQ-C30 Global } \\
\text { health status/QoL }\end{array}$} & ill & 98 & 54.6 & 23.9 & 0.0 & 50.0 & 100.0 & \multirow[t]{2}{*}{0.027} \\
\hline & healthy & 100 & 62.0 & 21.9 & 0.0 & 66.7 & 100.0 & \\
\hline \multirow{2}{*}{$\begin{array}{l}\text { QLQ-C30 Physical } \\
\text { function }\end{array}$} & ill & 100 & 67.5 & 20.2 & 6.7 & 66.7 & 100.0 & \multirow[t]{2}{*}{$<0.001$} \\
\hline & healthy & 100 & 83.9 & 15.3 & 26.7 & 86.7 & 100.0 & \\
\hline \multirow{2}{*}{$\begin{array}{l}\text { QLQ-C30 Role } \\
\text { function }\end{array}$} & ill & 100 & 65.7 & 30.9 & 0.0 & 66.7 & 100.0 & \multirow[t]{2}{*}{0.000} \\
\hline & healthy & 100 & 85.3 & 18.7 & 16.7 & 100.0 & 100.0 & \\
\hline \multirow{2}{*}{$\begin{array}{l}\text { QLQ-C30 Emotional } \\
\text { function }\end{array}$} & ill & 97 & 58.0 & 25.7 & 0.0 & 66.7 & 100.0 & \multirow[t]{2}{*}{0.001} \\
\hline & healthy & 100 & 70.2 & 22.8 & 8.3 & 70.8 & 100.0 & \\
\hline \multirow{2}{*}{$\begin{array}{l}\text { QLQ-C30 Cognitive } \\
\text { function }\end{array}$} & ill & 99 & 72.6 & 27.5 & 0.0 & 83.3 & 100.0 & \multirow[t]{2}{*}{0.066} \\
\hline & healthy & 100 & 79.8 & 22.3 & 0.0 & 83.3 & 100.0 & \\
\hline \multirow{2}{*}{$\begin{array}{l}\text { QLQ-C30 Social } \\
\text { function }\end{array}$} & ill & 97 & 62.5 & 33.5 & 0.0 & 66.7 & 100.0 & \multirow[t]{2}{*}{0.000} \\
\hline & healthy & 96 & 84.0 & 19.6 & 0.0 & 100.0 & 100.0 & \\
\hline \multirow[t]{2}{*}{ QLQ-C30 Fatigue } & ill & 100 & 45.8 & 24.2 & 0.0 & 33.3 & 100.0 & \multirow[t]{2}{*}{0.000} \\
\hline & healthy & 100 & 32.7 & 24.4 & 0.0 & 33.3 & 100.0 & \\
\hline \multirow{2}{*}{$\begin{array}{l}\text { QLQ-C30 Nausea/ } \\
\text { /vomiting }\end{array}$} & ill & 100 & 17.5 & 22.4 & 0.0 & 0.0 & 100.0 & \multirow[t]{2}{*}{0.000} \\
\hline & healthy & 100 & 7.0 & 15.0 & 0.0 & 0.0 & 83.3 & \\
\hline \multirow[t]{2}{*}{ QLQ-C30 Pain } & ill & 100 & 27.7 & 25.5 & 0.0 & 33.3 & 100.0 & \multirow[t]{2}{*}{0.008} \\
\hline & healthy & 100 & 18.7 & 21.1 & 0.0 & 16.7 & 100.0 & \\
\hline \multirow[t]{2}{*}{ QLQ-C30 Dyspnoea } & ill & 98 & 19.4 & 27.9 & 0.0 & 0.0 & 100.0 & \multirow[t]{2}{*}{0.011} \\
\hline & healthy & 100 & 10.3 & 20.5 & 0.0 & 0.0 & 100.0 & \\
\hline
\end{tabular}




\begin{tabular}{|c|c|c|c|c|c|c|c|c|}
\hline Group & & $n$ & Mean & $\begin{array}{l}\text { Standard } \\
\text { deviation }\end{array}$ & Min & Median & Max & $p^{*}$ \\
\hline \multirow[t]{2}{*}{ QLQ-C30 Insomnia } & ill & 98 & 42.9 & 36.5 & 0.0 & 33.3 & 100.0 & \multirow[t]{2}{*}{0.001} \\
\hline & healthy & 99 & 26.3 & 31.0 & 0.0 & 33.3 & 100.0 & \\
\hline \multirow{2}{*}{$\begin{array}{l}\text { QLQ-C30 Appetite } \\
\text { loss }\end{array}$} & ill & 98 & 30.3 & 30.7 & 0.0 & 33.3 & 100.0 & \multirow[t]{2}{*}{0.000} \\
\hline & healthy & 98 & 13.6 & 22.4 & 0.0 & 0.0 & 100.0 & \\
\hline \multirow{2}{*}{$\begin{array}{l}\text { QLQ-C30 Constipa- } \\
\text { tion }\end{array}$} & ill & 97 & 28.2 & 30.2 & 0.0 & 33.3 & 100.0 & \multirow[t]{2}{*}{0.212} \\
\hline & healthy & 100 & 22.7 & 26.8 & 0.0 & 33.3 & 100.0 & \\
\hline \multirow[t]{2}{*}{ QLQ-C30 Diarrhoea } & ill & 92 & 14.5 & 20.0 & 0.0 & 0.0 & 66.7 & \multirow[t]{2}{*}{0.287} \\
\hline & healthy & 100 & 11.0 & 16.4 & 0.0 & 0.0 & 66.7 & \\
\hline \multirow{2}{*}{$\begin{array}{l}\text { QLQ-C30 Financial } \\
\text { problems }\end{array}$} & ill & 94 & 31.2 & 33.4 & 0.0 & 33.3 & 100.0 & \multirow[t]{2}{*}{0.001} \\
\hline & healthy & 93 & 16.1 & 24.4 & 0.0 & 0.0 & 100.0 & \\
\hline
\end{tabular}

\begin{tabular}{|c|c|c|c|c|c|c|c|c|}
\hline Group & & $n$ & Mean & $\begin{array}{l}\text { Standard } \\
\text { deviation }\end{array}$ & Min & Median & Max & $p^{*}$ \\
\hline \multirow{2}{*}{$\begin{array}{l}\text { QLQ-OV28 Abdomi- } \\
\mathrm{nal} / \mathrm{GI}\end{array}$} & ill & 97 & 22.8 & 18.0 & 0.0 & 16.7 & 75.0 & \multirow[t]{2}{*}{0.073} \\
\hline & healthy & 100 & 18.9 & 17.8 & 0.0 & 16.7 & 83.3 & \\
\hline \multirow{2}{*}{$\begin{array}{l}\text { QLQ-OV28 Periph- } \\
\text { eral neuropathy }\end{array}$} & ill & 98 & 33.2 & 30.9 & 0.0 & 33.3 & 100.0 & \multirow[t]{2}{*}{0.000} \\
\hline & healthy & 99 & 12.5 & 22.5 & 0.0 & 0.0 & 100.0 & \\
\hline \multirow{2}{*}{$\begin{array}{l}\text { QLQ-OV28 Hor- } \\
\text { monal }\end{array}$} & ill & 98 & 36.2 & 30.6 & 0.0 & 33.3 & 100.0 & \multirow[t]{2}{*}{0.000} \\
\hline & healthy & 99 & 17.5 & 26.6 & 0.0 & 0.0 & 100.0 & \\
\hline \multirow{2}{*}{$\begin{array}{l}\text { QLQ-OV28 Body } \\
\text { image }\end{array}$} & ill & 99 & 38.6 & 30.1 & 0.0 & 33.3 & 100.0 & \multirow[t]{2}{*}{0.000} \\
\hline & healthy & 95 & 18.9 & 24.0 & 0.0 & 16.7 & 100.0 & \\
\hline \multirow{2}{*}{$\begin{array}{l}\text { QLQ-OV28 Attitude } \\
\text { to disease/treat- } \\
\text { ment }\end{array}$} & ill & 98 & 63.7 & 25.2 & 0.0 & 66.7 & 100.0 & \multirow[t]{2}{*}{0.000} \\
\hline & healthy & 82 & 24.1 & 31.1 & 0.0 & 11.1 & 100.0 & \\
\hline \multirow{2}{*}{$\begin{array}{l}\text { QLQ-OV28 Side } \\
\text { effects of chemo- } \\
\text { therapy }\end{array}$} & ill & 98 & 34.5 & 22.3 & 0.0 & 33.3 & 93.3 & \multirow[t]{2}{*}{0.000} \\
\hline & healthy & 99 & 15.8 & 19.1 & 0.0 & 13.3 & 93.3 & \\
\hline \multirow{2}{*}{$\begin{array}{l}\text { QLQ-OV28 Other } \\
\text { single items }\end{array}$} & ill & 98 & 36.4 & 27.0 & 0.0 & 33.3 & 91.7 & \multirow[t]{2}{*}{0.000} \\
\hline & healthy & 99 & 15.2 & 18.0 & 0.0 & 11.1 & 75.0 & \\
\hline \multirow[t]{2}{*}{ QLQ-OV28 Sexuality } & ill & 93 & 12.3 & 19.5 & 0.0 & 0.0 & 66.7 & \multirow[t]{2}{*}{0.000} \\
\hline & healthy & 93 & 32.6 & 22.7 & 0.0 & 33.3 & 91.7 & \\
\hline
\end{tabular}

* Mann-Whitney test.

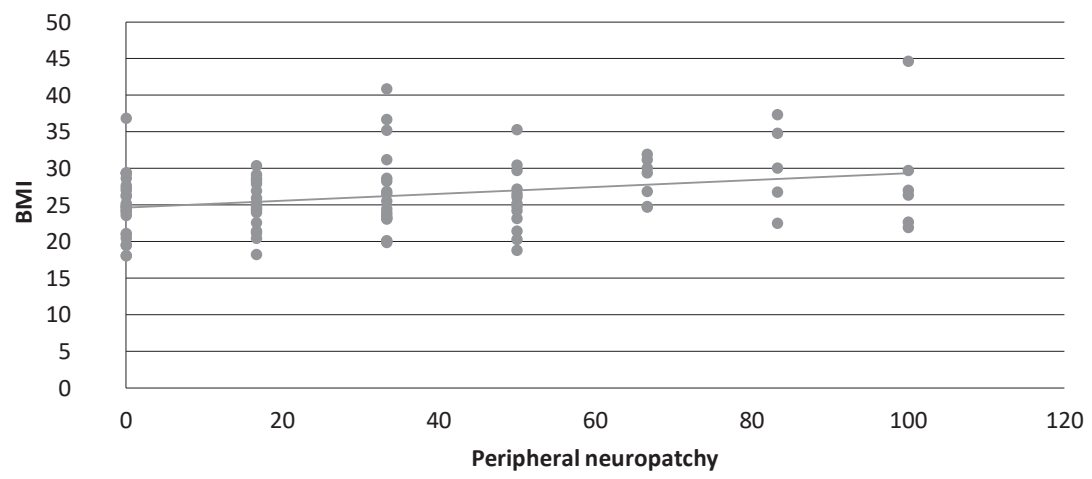

Figure 1. Relation between the BMI of ovarian cancer patients and peripheral neuropathy

Table 2 presents the mean results of the studied variables, as well as the median and standard deviations. In this study, higher values mean poorer quality of life. The table shows a comparison of quality of life for healthy women and those with ovarian cancer based on the QLQ-OV28 questionnaire. The study showed that the quality of life of women who are ill compared to healthy women is reduced. The assessment of the dependencies, in which such quantitative variables as BMI or the time elapsed since the diagnosis of the disease were taken into account, are presented in scatterplots. The scale in this chart reflects the scale for a given variable and the mutual correlations between two variables. In the analysis of the relationship between the BMI index of patients with ovarian cancer and the occurrence of peripheral neuropathies and side effects of the applied chemotherapy, a so-called positive correlation was observed, which means that the increase in results for one variable is accompanied by an increase in the results for the second variable. In Figures 1 and 2, it can be seen that in more obese 

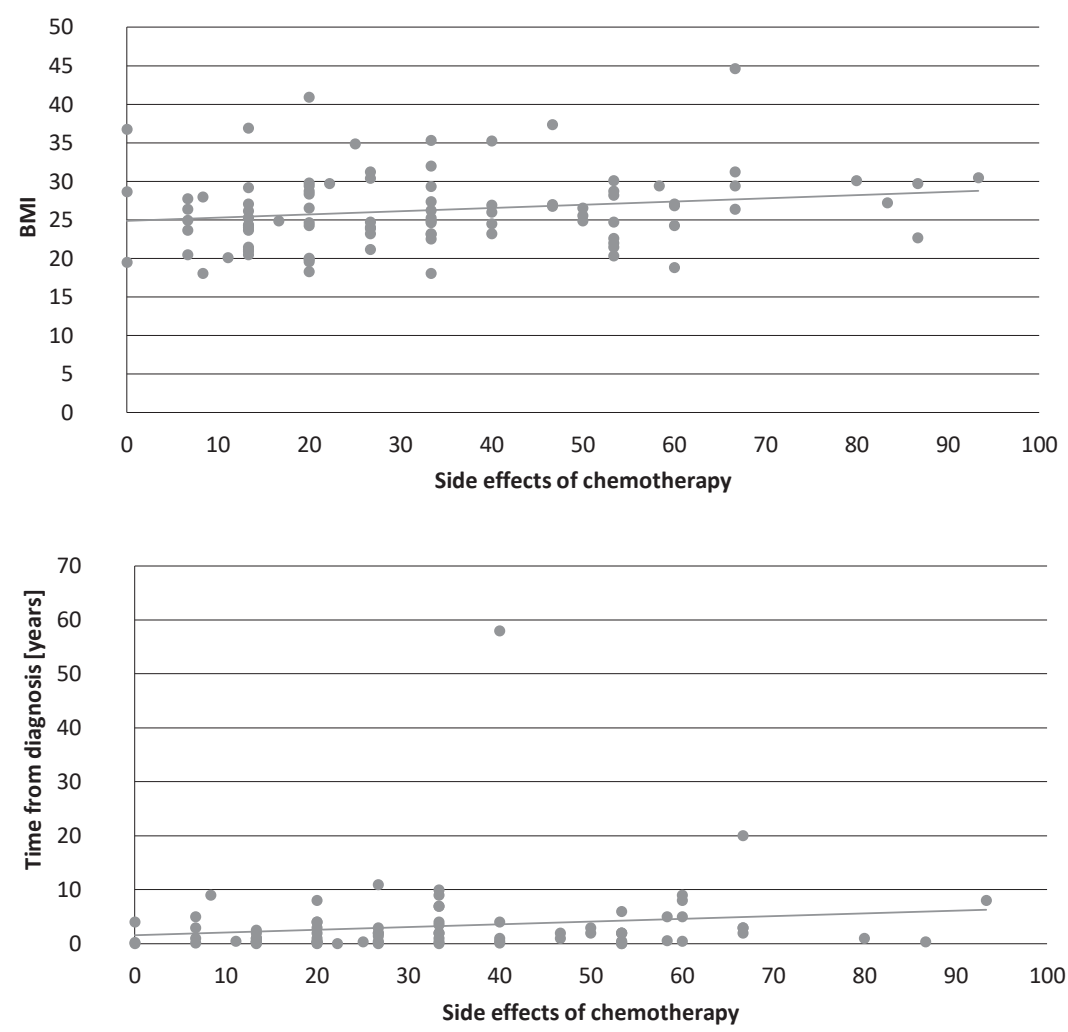

Figure 2. Relation between the BMI of ovarian cancer patients and side effects of chemotherapy
Figure 3. Relation between the time from diagnosis and side effects of chemotherapy in ovarian cancer patients patients, peripheral neuropathies and the side effects of chemotherapy were more severe. A negative correlation, on the other hand, is visible in Figure 3. The research showed that the longer time that had elapsed from the diagnosis of the disease, the worse the patients coped with chemotherapy. In 3 respondents, this took even more than 10 years (hence the data regarding the years has been presented in dozens). The time that passed since the diagnosis of the disease in most patients was about 5 years.

\section{Discussion}

\section{Key results}

Ovarian cancer treatment causes many problems, such as the side effects of chemotherapy or ailments connected with the disease itself, which significantly lower quality of life. Studies concerning this issue make it possible to assess the impact of the disease and the treatment on the patient's condition. Moreover, the respondents filled in a questionnaire concerning sociodemographic data, such as body mass and the time from diagnosis.

The work involved evaluating ovarian cancer patients' quality of life and comparing the symptoms they reported in EORTC QLQ-C30 and EORTC QLQ-OV28 scales with the data obtained through the sociometric questionnaire.

\section{Interpretation}

The evaluation of the respondents' overall quality of life showed that the quality of life of women with ovarian cancer is much lower than that of healthy women. The only areas which both ill and healthy women described similarly were digestive system problems and cognitive function. The obtained results were confirmed by a study carried out by Nho et al. [6]. The subjects experienced symptoms such as anxiety, depression, fatigue, sleep disorders, pain and peripheral neuropathies induced by chemotherapy. Different results were obtained in a review paper by Kumar et al. showing no meaningful difference in quality of life scores between patients undergoing standard or extensive surgery at 6 months [7]. On the other hand, Pynnä et al. [8] showed that depression, vitality and sexual activity were impaired at baseline but improved during follow-up.

In the presented study, ovarian cancer patients with higher body mass index were predisposed to more intensive peripheral neuropathy symptoms and side effects of chemotherapy. Similar conclusions were drawn by Smits et al. [9], who proved that obesity is related to a significantly worse result of overall quality of life and reduced physical, cognitive and social function. They suggest that interventions promoting physical activity and the reduction of body mass should be implemented in the future as one method of improving the quality of life of ovarian cancer patients. According to Ezendam et al. [10], symptoms of peripheral neuropathy affect more than half of women treated for ovarian cancer with chemotherapy. The patients complained about a reduced level of functioning, as well as the severity of symptoms of tiredness, nausea, vomiting, pain, breathlessness, insomnia, loss of appetite and financial problems. On the other hand, in the work of Donkers et al., overweight and obese women reported improvement in sexual function compared to women with normal body weight with endometrial, ovarian and vulvar cancer. Among cervical cancers, worse sexual functioning was observed in women with increased BMI [11]. In Grabowski's et al. analysis, patients with lower BMI were treated with fewer cycles of chemotherapy, and cytostatics were more frequently discontinued. At the same time, haematological toxicity and higher drug intake were more common in patients with higher BMI [12]. Kiechle et al. undertook studies evaluating the strategy of physical fitness, eating habits and psychological factors in women at high risk of developing breast or ovarian cancer. The results of this pilot feasibility study will be the basis for a broader prospective randomised trial including clinical events [13].

Our study showed that the longer the time lapse between diagnosis and the beginning of treatment led to more intensive side effects of chemotherapy, which was the result of intensive antineoplastic treatment that had to be implemented. Hwang et al. [14] identified seven intensifying groups of symptoms in patients undergoing chemotherapy: emotional suffering, fatigue, pain, abdominal discomfort, flu-like symptoms, ascites and peripheral neuropathy. Respondents with high levels of anxiety or depression experienced all the symptoms the most. 
Nho et al. observed an increase in complaints depending on age, age at onset, disease duration, recurrence and performance status of patients with ovarian cancer [6]. Teng et al. [15] showed that psychosocial factors have a greater impact on quality of life than physical symptoms. Clinical factors such as age, clinical stage of cancer, type of cancer and its histological differentiation do not significantly affect the quality of life of the respondents.

\section{Conclusions}

Patients undergoing treatment for ovarian cancer have significantly lower quality of life than healthy women. Sociodemographic determinants such as body mass and the time from diagnosis predispose patients to intensified symptoms which lower the quality of life of ovarian cancer patients.

Source of funding: This work was funded from the authors' own resources.

Conflicts of interest: The authors declare no conflicts of interest.

\section{References}

1. Ferlay J, Soerjomataram I, Ervik M, et al. GLOBOCAN 2012 v1.0, Cancer Incidence and Mortality Worldwide: IARC CancerBase No. 11 [Internet]. Lyon, France: International Agency for Research on Cancer 2013 [cited 15.03.2016]. Available from URL: http://globocan. iarc.fr.

2. Reports based on data of National Cancer Registry. The Maria Sklodowska-Curie Memorial Cancer Center. Department of Epidemiology and Cancer Prevetion, National Cancer Registry 2011 [cited 12.02.2016]. Available from URL:. http://epid.coi.waw.pl/krn.

3. Gershenson DM. Treatment of ovarian cancer in young women. Clin Obstet Gynecol 2012; 55(1): 65-74.

4. Ferlay J, Steliarova-Foucher E, Lortet-Tieulent J, et al. Cancer incidence and mortality patterns in Europe: estimates for 40 countries in 2012. Eur J Cancer 2013; 49(6): 1374-1403.

5. Oza AM, Matulonis UA, Malander S, et al. Quality of life in patients with recurrent ovarian cancer treated with niraparib versus placebo (ENGOT-OV16/NOVA): results from a double-blind, phase 3, randomised controlled trial. Lancet Oncol 2018; 19(8): 1117-1125, doi: 10.1016/S1470-2045(18)30333-4.

6. Nho JH, Reul Kim S, Nam JH. Symptom clustering and quality of life in patients with ovarian cancer undergoing chemotherapy. Eur J Oncol Nurs 2017; 30: 8-14, doi: 10.1016/j.ejon.2017.07.007.

7. Kumar S, Long J, Kehoe S, et al. Quality of life outcomes following surgery for advanced ovarian cancer: a systematic review and metaanalysis. Int J Gynecol Cancer 2019, doi: 10.1136/ijgc-2018-000125.

8. Pynnä K, Vuorela P, Aronen P, et al. Treatment of gynecological malignancies: long-term follow-up of health-related quality of life and healthcare costs. J Comp Eff Res 2019; 8(7): 475-486, doi: 10.2217/cer-2018-0125.

9. Smits A, Smits E, Lopes A, et al. Body mass index, physical activity and quality of life of ovarian cancer survivors: time to get moving? Gynecol Oncol 2015; 139(1): 148-154.

10. Ezendam NP, Pijlman B, Bhugwandass C, et al. Chemotherapy-induced peripheral neuropathy and its impact on health-related quality of life among ovarian cancer survivors: results from the population-based PROFILES registry. Gynecol Oncol 2014; 135(3): 510-517.

11. Donkers H, Smits A, Eleuteri A, et al. Galaal. Body mass index and sexual function in women with gynaecological cancer. Psychooncology 2019; 28(1): 48-53, doi: 10.1002/pon.4908.

12. Grabowski JP, Richter R, Rittmeister H, et al. Impact of Body Mass Index (BMI) on chemotherapy-associated toxicity in ovarian cancer patients. A pooled analysis of the North-Eastern German Society of Gynecological Oncology (NOGGO) Databank on 1,213 Patients. Anticancer Res 2018; 38(10): 5853-5858, doi: 10.21873/anticanres.12927.

13. Kiechle M, Engel C, Berling A, et al. Lifestyle intervention in BRCA1/2 mutation carriers: study protocol for a prospective, randomized, controlled clinical feasibility trial (LIBRE-1 study). Pilot Feasibility Stud 2016; 2: 74, doi: 10.1186/s40814-016-0114-7.

14. Hwang KH, Cho OH, Yoo YS. Symptom clusters of ovarian cancer patients undergoing chemotherapy, and their emotional status and quality of life. Eur J Oncol Nurs 2016; 21: 215-22.

15. Teng FF, Kalloger SE, Brotto L, et al. Determinants of quality of life in ovarian cancer survivors: a pilot study. J Obstet Gynaecol Can 2014; 36(8): 708-715.

Tables: 2

Figures: 3

References: 15

Received: 25.04.2019

Reviewed: 20.05.2019

Accepted: 18.08.2019

Address for correspondence:

Ewa Perkowska, PhD

Zakład Podstawowej Opieki Zdrowotnej

Uniwersytet Medyczny

ul. Mieszka I 4B

15-054 Białystok

Polska

Tel.: +48 85 732-68-20

E-mail: ewa.perkowska@umb.edu.pl 